\title{
PEMBERDAYAAN MASYARAKAT PETANI DAN PETERNAK DALAM PELAKSANAAN SANITASI TOTAL BERBASIS MASYARAKAT DI DESA SINDUHARJO
}

\author{
Fatwa Tentama*, Ahmad Faizal Rangkuti ${ }^{2}$, Surahma Asti Mulasari ${ }^{3}$, \\ Tri Wahyuni Sukesi ${ }^{4}$, Sulistyawati ${ }^{5}$ \\ ${ }^{12345}$ Universitas Ahmad Dahlan Yogyakarta \\ faizal.rangkuti@ikm.uad.ac.id
}

\begin{abstract}
ABSTRAK
Dusun Dukuh, Taraman dan Ngemplak merupakan dusun yang berada di wilayah Desa Sinduharjo. Sanitasi Total Berbasis Masyarakat (STBM) adalah upaya peningkatan derajat kesehatan masyarakat yang menitikberatkan pada partisipasi masyarakat itu sendiri. Tiga dusun tersebut sebagian besar mata pencaharian penduduknya adalah bertani dan beternak. Rata rata penduduk di sana memiliki hewan ternak yang dipelihara baik di kelompok kandang atau dipelihara di sekitar rumahnya. Menurut observasi yang dilakukan di ketiga lokasi tersebut, ternak tersebut belum dikelola secara maksimal dalam hal sanitasinya sehingga kemungkinan mencemari lingkungan sangatlah tinggi apalagi untuk ternak yang dipelihara di sekitar pekarangan rumah. Pada musim panen tiba hasil panenannya sangat melimpah. Akan tetapi hasil yang melimpah ini juga meninggalkan permasalahan baru yaitu limbah yang tidak dikelola dengan baik. Pemanfaatan limbah pertanian dan peternakan masih sangat terbatas,. Hal ini dikarenakan minimnya kesadaran, pengetahuan,dan ketrampilan untuk memanfaatkan limbah tersebut. Tujuan dari KKN PPM ini adalah meningkatkan pemberdayaan masyarakat petani dan peternak dalam melaksanakan sanitasi total berbasis masyarakat dalam rangka mengendalikan pencemaran lingkungan dengan memanfaatkan limbah pertanian dan peternakan menjadi barang barang bernilai ekonomis dan memiliki kemanfaatan yang lebih dari sebelumnya seperti briket, bokashi, silase, pupuk cascing, dan biogas. Agar kegiatan ini dapat berkelanjutan program ini akan bekerjasama dengan organisasi pemuda, kelompok ternak dan kelompok tani di Dusun Dukuh, Taraman dan Ngemplak, Dinas Pertanian dan Dinas Perternakan Kabupaten Sleman yang nantinya akan dapat membantu dalam kelancaran proses pelaksanaan program pelatihan bahkan sampai kepada pemasaran untuk meningkatkan produksi pertanian dan peternakan masyarakat setempat. Metode yang dipergunakan pada program KKN PPM ini adalah penyuluhan, pelatihan dan pendampingan yang akan dilakukan oleh mahasiswa KKN UAD, didampingi oleh dosen UAD. kegiatan ini juga akan membantu kegiatan pasca produksinya.
\end{abstract}

Kata kunci : briket, bokashi, silase, limbah, pupuk cascing, biogas, pertanian, peternakan

\begin{abstract}
Dukuh, Taraman and Ngemplak Hamlets are hamlets located in Sinduharjo Village. Community Based Total Sanitation (STBM) is an effort to improve the degree of community health which focuses on community participation itself. The three hamlets, the majority of the livelihoods of the people are farming and raising livestock. The average population there has livestock that are kept either in the cage group or kept around the house. According to observations made in these three locations, these livestock have not been managed optimally in terms of sanitation so the possibility of polluting the environment is very high especially for livestock that are kept around the yard. In the harvest season the yields are very abundant. However, these abundant results also leave new problems, namely waste that is not managed properly. The use of agricultural and livestock waste is still very limited. This is due to the lack of awareness, knowledge and skills to utilize the waste. The purpose of this PPM KKN is to improve the empowerment of farmers and farmers in carrying out community-based total sanitation in order to control environmental pollution by utilizing agricultural and livestock waste into economic value goods and having more benefits than before such as briquettes, bokashi, silage, cascing fertilizer and biogas. In order for this activity to be sustainable this program will cooperate with youth organizations, livestock groups and farmer groups in Dukuh, Taraman and Ngemplak Hamlets, the Agriculture Service and Livestock Services of Sleman Regency which will later be able to assist
\end{abstract}


Prosiding Seminar Nasional seri 8

"Mewujudkan Masyarakat Madani dan Lestari” Yogyakarta, 27 September 2018

Diseminasi Hasil-Hasil Pengabdian

in the smooth implementation of training programs even to marketing to improve local community agricultural and livestock production. The method used in the PPM KKN program is counseling, training and mentoring to be carried out by UAD KKN students, accompanied by UAD lecturers. this activity will also help post-production activities.

Keywords : briquettes, bokashi, silage, waste, cascing fertilizer, biogas, agriculture, livestock

\section{PENDAHULUAN}

Kabupaten Sleman memiliki lahan pertanian yang paling luas dibandingakn dengan 3 kabupaten 1 Kota di Daerah Istimewa Yogyakarta. Total luas lahan pertanian di wilayah Sleman adalah 39.462 (Dinas Pertanian Kab.Sleman, 2015). Desa Sinduharjo menurut data dari profil desa Sinduharjo tahun 2014 menunjukkan luas wilayah $6.090 \mathrm{~m}^{2}$ dengan jumlah penduduk sebanyak 18.920 jiwa. Wilayah Desa Sinduharjo terletak disebelah utara kota Yogyakarta dan terbelah oleh jalan Kaliurang yang menuju kekawasan wisata Kaliurang. Disamping itu kondisi masyarakatnya juga cukup beragam dengan penduduknya yang cukup padat, dengan kondisi sosialnya yang cukup komplek dengan mata pencaharian yang beraneka ragam tetapi mayoritas adalah petani, peternak dan buruh tani. Desa Sinduharjo terbagi menjadi 17 padukuhan dan yang digunakan dalam KKN PPM ini adalah Padukuhan Dukuh, Taraman dan Ngemplak.

Dusun Taraman berdasarkan data Desa Sinduharjo tahun 2017 memiliki jumlah penduduk sebanyak 581 jiwa dengan jumlah laki laki 342 dan jumlah perempuan 339 jiwa. Tingkat pendidikan dari warga Dusun Taraman adalah sebagai berikut :

\section{Tabel 1. Tingkat Pendidikan Warga Di Dusun Taraman}

\begin{tabular}{|c|c|c|c|c|c|}
\hline Tidak Sekolah & Tidak tamat SD & SD & SMP & SMA & $>$ SMA \\
\hline 142 & 75 & 43 & 60 & 210 & 151 \\
\hline
\end{tabular}

Mata pencaharian yang paling dominan di Dusun ini adalah petani dan peternak. Wilayah Dusun Taraman ini memiliki area pertanian yang cukup luas dan sebagian besar dari warganya memiliki binatang ternak. Dusun Dukuh memiliki jumlah penduduk sebesar 514 jiwa diantaranya adalah laki laki sebanyak 261 jiwa dan perempuan sebanyak 253 jiwa. Tingkat pendidikan warga Dusun Dukuh adalah sebagai berikut : 


\section{Tabel 2. Tingkat Pendidikan Warga Di Dusun Dukuh}

\begin{tabular}{|c|c|c|c|c|c|}
\hline Tidak Sekolah & Tidak tamat SD & SD & SMP & SMA & >SMA \\
\hline 105 & 52 & 54 & 56 & 159 & 98 \\
\hline
\end{tabular}

Mata pencaharian yang paling dominan di Dusun ini adalah petani dan peternak. Wilayah Dusun Dukuh ini memiliki area pertanian yang cukup luas dan sebagian besar dari warganya memiliki binatang ternak. Sedangkan dusun Ngemplak memiliki jumlah penduduknya adalah 472 jiwa yang terdiri dari laki laki 223 jiwa dan perempuan sebanyak 249 jiwa. Tingkat pendidikan warga Dusun Ngemplak adalah sebagai berikut

Tabel 3. Tingkat Pendidikan Warga Di Dusun Ngemplak

\begin{tabular}{|c|c|c|c|c|c|}
\hline Tidak Sekolah & $\begin{array}{c}\text { Tidak tamat } \\
\text { SD }\end{array}$ & SD & SMP & SMA & >SMA \\
\hline 90 & 49 & 70 & 57 & 48 & 58 \\
\hline
\end{tabular}

Mata pencaharian yang paling dominan di Dusun ini adalah petani dan peternak. Wilayah Dusun Ngemplak ini memiliki area pertanian yang cukup luas dan sebagian besar dari warganya memiliki binatang ternak.

Gambaran permasalahan yang ada di lokasi mitra dapat dilihat sebagai berikut
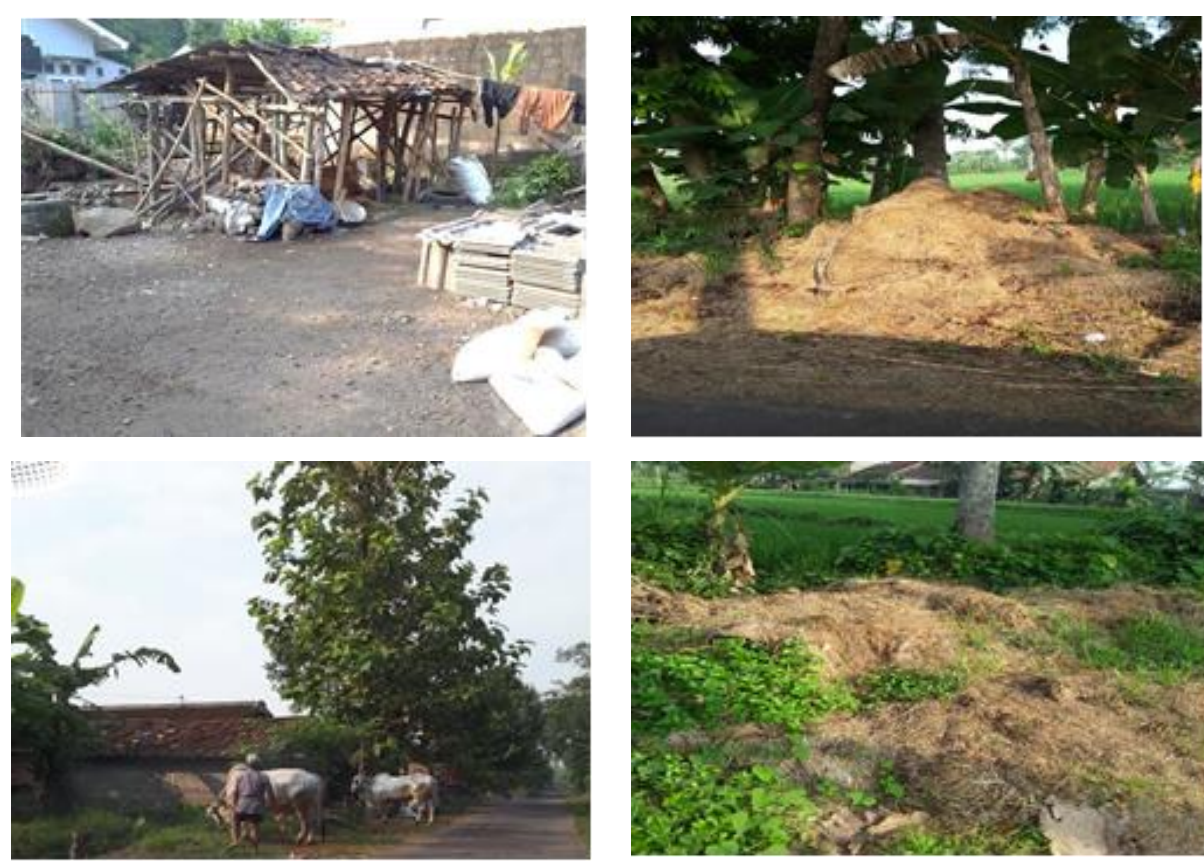

Gambar 1. Gambaran Permasalahan di Lokasi Mitra 
Permasalahan yang jelas dihadapi oleh desa mitra yaitu adalah limbah pertanian dan peternakan yang tidak dikelola dnegan baik, dibuang begitu saja hingga membusuk dan menimbulkan bau di lingkungan sekitar. Terkadang limbah tersebut hanya dibakar yang dapat menyebabkan pencemaran lingkungan. Pengelolaan ternak juga belum bagus karena masih banyak ternak yang dikandangkan di dekat dengan rumah yang kotorannya dapat tersebar dan mencemari lingkungan rumah. Kotoran ternak juga hanya dibiarkan begitu saja sebelum dibawa ke sawah untuk pupuk dan saat musim hujan kotoran tersebut terkena air hujan dan tersebar disepanjang air hujan tersebut mengalir serta menimbulkan bau yang tidak sedap. Hal ini disebabkan karena memang tingkat pengetahuan dan keterampilan tentang pengelolaan limbah pertanian dan peternakan warga di lokasi mitra masih sangat minim.

\section{Tabel 4. Rincian Permasalahan Desa Mitra}

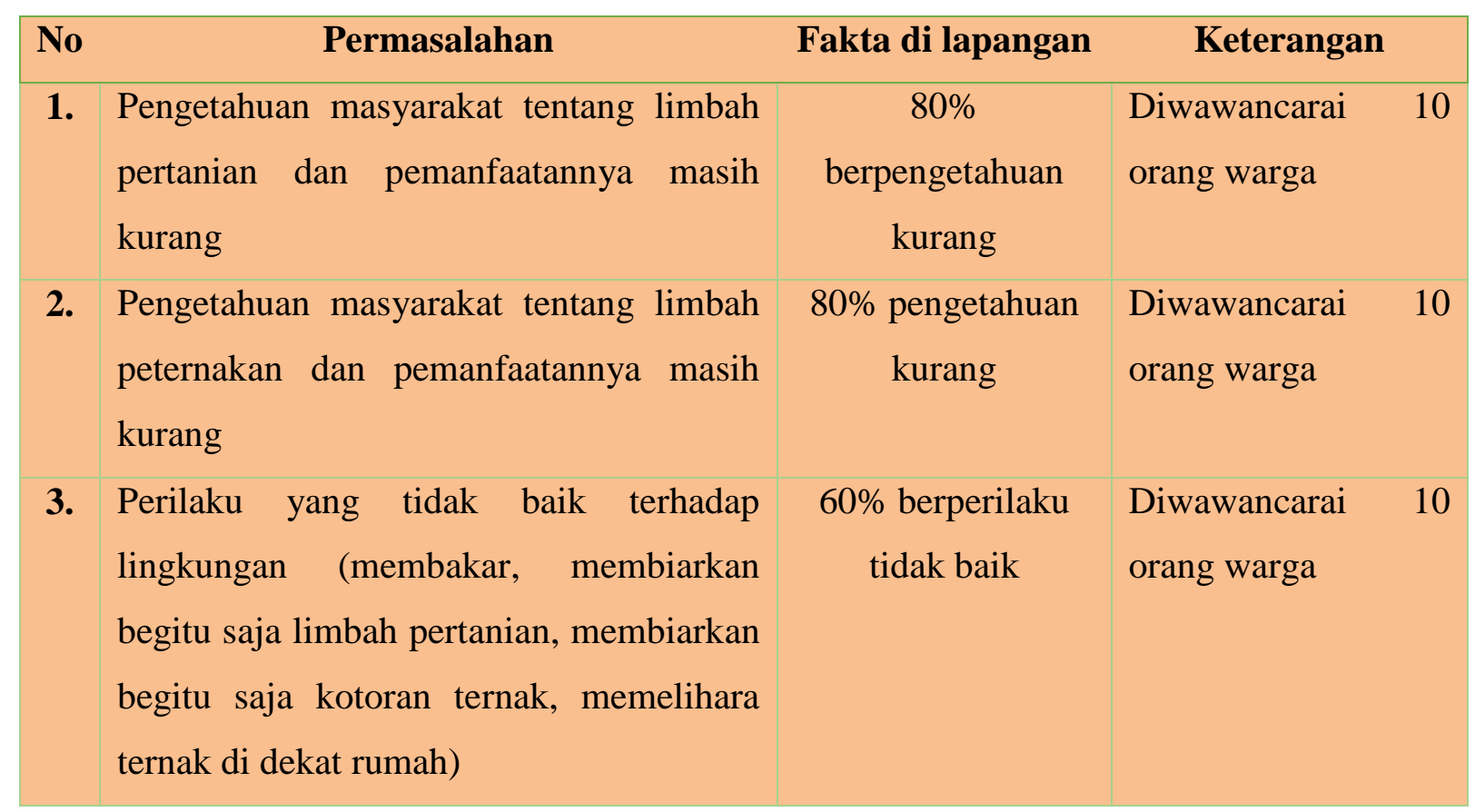

Berdasarkan permasalahan di atas maka diperlukan pengetahuan dan ketrampilan dalam pengolahan dan pemanfaatan limbah ternak dan pertanian menjadi produk-produk yang memiliki nilai jual bagi masyarakat di desa Sinduharjo khususnya dusun Taraman, Dukuh dan Ngemplak melalui program KKN PPM yang merupakan program pengabdian masyarakat yang dilakukan oleh mahasiswa dan dosen.

\section{METODE PELAKSANAAN}

\section{Persiapan dan Pembekalan}

a. Mekanisme pelaksanaan kegiatan KKN-PPM 
Kegiatan KKN PPM ini dilaksanakan oleh 27 orang mahasiswa KKN UAD. Pelaksanaan kegiatan KKN PPM akan berlangsung selama satu bulan. Pada tahap persiapan dan pembekalan akan dilakukan berbagai pelatihan pada mahasiswa KKN menyangkut berbagai program yang akan dilaksanakan.

\section{b. Materi persiapan dan pembekalan KKN-PPM yang perlu diberikan kepada mahasiswa}

Materi pembekalan yang akan diberikan berupa penjelasan tentang program KKN PPM, antara lain latar belakang, tujuan kegiatan dan manfaat kegiatan serta berbagai program yang akan dilaksanakan. Selain itu mahasiswa juga akan diberi penjelasan tentang kondisi sosio kultural dan ekonomi masyarakat Dusun Dukuh, Taraman dan Ngemplak. Pelatihan pengolahan limbah pertanian dan peternakan menjadi produk diberikan pada akhir kegiatan pembekalan.

\section{c. Jadwal pelaksanaan kegiatan KKN PPM}

Kegiatan KKN PPM dilakukan pada bulan Agustus tahun 2018. Sebelumnya dilakukan kegiatan persiapan dan pembekalan pada bulan Mei-Juli 2018. Pemantauan kegiatan terus dilakukan sampai bulan September 2018.

Pelaksanaan persiapan dan pembekalan KKN-PPM Universitas Ahmad Dahlan

\section{Pembekalan KKN}

Pembekalan KKN UAD dengan bobot 1 sks dan dengan rincian waktu sebagai berikut.

a. Kegiatan terjadwal dengan kegiatan berupa tatap muka untuk pemberian teori: $50 \times 16 \times 1$ $=800$ menit.

b. Kegiatan tidak terjadwal terstruktur dengan waktu 60 menit x 16 x $1=960$ menit.

c. Kegiatan tidak terjadwal mandiri dengan waktu 60 menit x 16 x $1=960$ menit.

Total waktu kegiatan pembekalan KKN UAD: 2720 menit (45 jam 20 menit). Materi pembekalan KKN meliputi kegiatan terjadwal, kegiatan tidak terjadwal terstruktur, dan kegiatan tidak terjadwal mandiri.

Kegiatan terjadwal meliputi pemberian teori berupa (a) Wawasan KKN, (2) Survei dan Analisis Sosial, (3) Penyusunan Program dan Proposal Kegiatan, (4) Administrasi dan Kelengkapan Pendukung KKN, (5) Laporan Kegiatan, (6) Komunikasi Lisan, Komunikasi Tulis, Kewirausahaan, dan Wawasan Kesehatan, (7) Wawasan Daerah, (8) Responsi, dan (9) Ta'aruf. Materi (1) sampai (7) masing-masing dilaksanakan dalam dengan waktu terjadwal 2 x 50 menit. Untuk materi (8) dan (9) masing-masing 1 x 50 menit. 
Prosiding Seminar Nasional seri 8

"Mewujudkan Masyarakat Madani dan Lestari” Yogyakarta, 27 September 2018

Diseminasi Hasil-Hasil Pengabdian

\section{Pelaksanaan}

Langkah-langkah dalam bentuk program dan metode yang digunakan dalam pemberdayaan sasaran.

Tabel 5. Program dan Metode

\begin{tabular}{|c|c|c|c|}
\hline Program & Sasaran & Mitra & Metode \\
\hline $\begin{array}{l}\text { Pelatihan pembuatan } \\
\text { briket biomassa }\end{array}$ & $\begin{array}{lr}\text { Kelompok petani dan } \\
\text { peternak } & \text { Dusun } \\
\text { Dukuh, } & \text { Ngemplak, } \\
\text { Taraman } & \end{array}$ & $\begin{array}{l}\text { Dinas Pertanian } \\
\text { Kabupaten } \\
\text { Sleman, dosen } \\
\text { FKM UAD }\end{array}$ & $\begin{array}{l}\text { - } \text { Ceramah } \\
\text { - } \quad \text { Pelatihan/Role Play } \\
\text { - } \quad \text { Diskusi } \\
\text { - Pendampingan }\end{array}$ \\
\hline $\begin{array}{l}\text { Pelatihan pembuatan } \\
\text { bokashi }\end{array}$ & $\begin{array}{lr}\text { Kelompok petani dan } \\
\text { peternak } \\
\text { Dukuh, } \\
\text { Taraman }\end{array}$ & $\begin{array}{l}\text { Dinas Pertanian } \\
\text { Kabupaten } \\
\text { Sleman, dosen } \\
\text { FKM UAD }\end{array}$ & $\begin{array}{ll}\text { - } & \text { Ceramah } \\
\text { - } & \text { Pelatihan/Role Play } \\
\text { - } & \text { Diskusi } \\
\text { - } & \text { Pendampingan }\end{array}$ \\
\hline $\begin{array}{l}\text { Pelatihan pembuatan } \\
\text { silase }\end{array}$ & $\begin{array}{lr}\text { Kelompok petani dan } \\
\text { peternak } & \text { Dusun } \\
\text { Dukuh, } & \text { Ngemplak, } \\
\text { Taraman } & \end{array}$ & $\begin{array}{l}\text { Dinas Peternakan } \\
\text { Kabupaten } \\
\text { Sleman, dosen } \\
\text { FKM UAD }\end{array}$ & $\begin{array}{l}\text { - } \text { Ceramah } \\
\text { - } \text { Pelatihan/Role Play } \\
\text { - } \text { Diskusi } \\
\text { - Pendampingan }\end{array}$ \\
\hline $\begin{array}{l}\text { Pelatihan pembuatan } \\
\text { pupuk cascing }\end{array}$ & $\begin{array}{lr}\text { Kelompok petani dan } \\
\text { peternak } & \text { Dusun } \\
\text { Dukuh, } & \text { Ngemplak, } \\
\text { Taraman } & \end{array}$ & $\begin{array}{l}\text { Dinas Pertanian } \\
\text { Kabupaten } \\
\text { Sleman, dosen } \\
\text { FKM UAD }\end{array}$ & $\begin{array}{ll}\text { - } & \text { Ceramah } \\
\text { - } & \text { Pelatihan/Role Play } \\
\text { - } & \text { Diskusi } \\
\text { - } & \text { Pendampingan }\end{array}$ \\
\hline $\begin{array}{l}\text { Pelatihan pembuatan } \\
\text { biogas }\end{array}$ & $\begin{array}{lr}\text { Kelompok petani dan } \\
\text { peternak } & \text { Dusun } \\
\text { Dukuh, } & \text { Ngemplak, } \\
\text { Taraman } & \end{array}$ & $\begin{array}{l}\text { Dinas Peternakan } \\
\text { Kabupaten } \\
\text { Sleman, dosen } \\
\text { FKM UAD }\end{array}$ & $\begin{array}{l}\text { - Ceramah } \\
\text { - Pelatihan/Role Play } \\
\text { - Diskusi } \\
\text { - Pendampingan }\end{array}$ \\
\hline $\begin{array}{l}\text { Pelatihan } \\
\text { "Meningkatkan } \\
\text { Motivasi } \\
\text { Wirausaha" untuk } \\
\text { Memanfaatkan } \\
\text { produk olahan } \\
\text { limbah pertanian } \\
\text { dan peternakan }\end{array}$ & $\begin{array}{lr}\text { Kelompok petani dan } \\
\text { peternak } & \text { Dusun } \\
\text { Dukuh, } & \text { Ngemplak, } \\
\text { Taraman } & \end{array}$ & $\begin{array}{l}\text { Dinas Pertanian } \\
\text { Kabupaten } \\
\text { Sleman, dosen } \\
\text { FKM UAD }\end{array}$ & $\begin{array}{l}\text { - } \text { Ceramah } \\
\text { - Pelatihan/Role Play } \\
\text { - Diskusi } \\
\text { - Pendampingan }\end{array}$ \\
\hline
\end{tabular}




\begin{tabular}{|c|c|c|c|c|}
\hline $\begin{array}{l}\text { Pelatihan } \\
\text { pemanfaatan briket } \\
\text { untuk alternatif } \\
\text { bahan bakar }\end{array}$ & $\begin{array}{l}\text { Kelompok } \\
\text { peternak } \\
\text { Dukuh, } \\
\text { Taraman }\end{array}$ & $\begin{array}{r}\text { petani dan } \\
\text { Dusun } \\
\text { Ngemplak, }\end{array}$ & $\begin{array}{l}\text { Dinas Pertanian } \\
\text { Kabupaten } \\
\text { Sleman, dosen } \\
\text { FKM UAD }\end{array}$ & $\begin{array}{l}\text { - } \text { Ceramah } \\
\text { - } \text { Pelatihan/Role Play } \\
\text { - } \text { Diskusi } \\
\text { - Pendampingan }\end{array}$ \\
\hline $\begin{array}{l}\text { Pelatihan } \\
\text { pemanfaatan } \\
\text { bokashi dan pupuk } \\
\text { cascing untuk media } \\
\text { tanam }\end{array}$ & $\begin{array}{l}\text { Kelompok } \\
\text { peternak } \\
\text { Dukuh, } \\
\text { Taraman, } \\
\text { pertanian } \\
\text { hidroponik } \\
\text { aquaponik }\end{array}$ & $\begin{array}{r}\text { petani dan } \\
\text { Dusun } \\
\text { Ngemplak, } \\
\text { Melakukan } \\
\text { sistem } \\
\text { dan }\end{array}$ & $\begin{array}{l}\text { Dinas Pertanian } \\
\text { Kabupaten } \\
\text { Sleman, dosen } \\
\text { FKM UAD }\end{array}$ & $\begin{array}{l}\text { - } \text { Ceramah } \\
\text { - } \text { Pelatihan/Role Play } \\
\text { - } \text { Diskusi } \\
\text { - } \text { Pendampingan }\end{array}$ \\
\hline $\begin{array}{l}\text { Pelatihan } \\
\text { pemanfaatan silase } \\
\text { untuk pakan ternak }\end{array}$ & $\begin{array}{l}\text { Kelompok } \\
\text { peternak } \\
\text { Dukuh, } \\
\text { Taraman }\end{array}$ & $\begin{array}{r}\text { petani dan } \\
\text { Dusun } \\
\text { Ngemplak, }\end{array}$ & $\begin{array}{l}\text { Dinas Peternakan } \\
\text { Kabupaten } \\
\text { Sleman, dosen } \\
\text { FKM UAD }\end{array}$ & $\begin{array}{ll}\text { - } & \text { Praktek } \\
& \text { Pelatihan/Role Play } \\
\text { - } & \text { Diskusi } \\
\text { - } & \text { Pendampingan }\end{array}$ \\
\hline $\begin{array}{l}\text { Penguatan kelompok } \\
\text { kandang dan } \\
\text { kelompok tani }\end{array}$ & $\begin{array}{l}\text { Kelompok } \\
\text { peternak } \\
\text { Dukuh, } \\
\text { Taraman }\end{array}$ & $\begin{array}{r}\text { petani dan } \\
\text { Dusun } \\
\text { Ngemplak, }\end{array}$ & $\begin{array}{l}\text { Pemerintah Desa } \\
\text { Sinduharjo, dosen } \\
\text { FKM UAD }\end{array}$ & $\begin{array}{ll}\text { - } & \text { Praktek } \\
& \text { Pelatihan/Role Play } \\
\text { - } & \text { Diskusi } \\
\text { - } & \text { Pendampingan }\end{array}$ \\
\hline
\end{tabular}

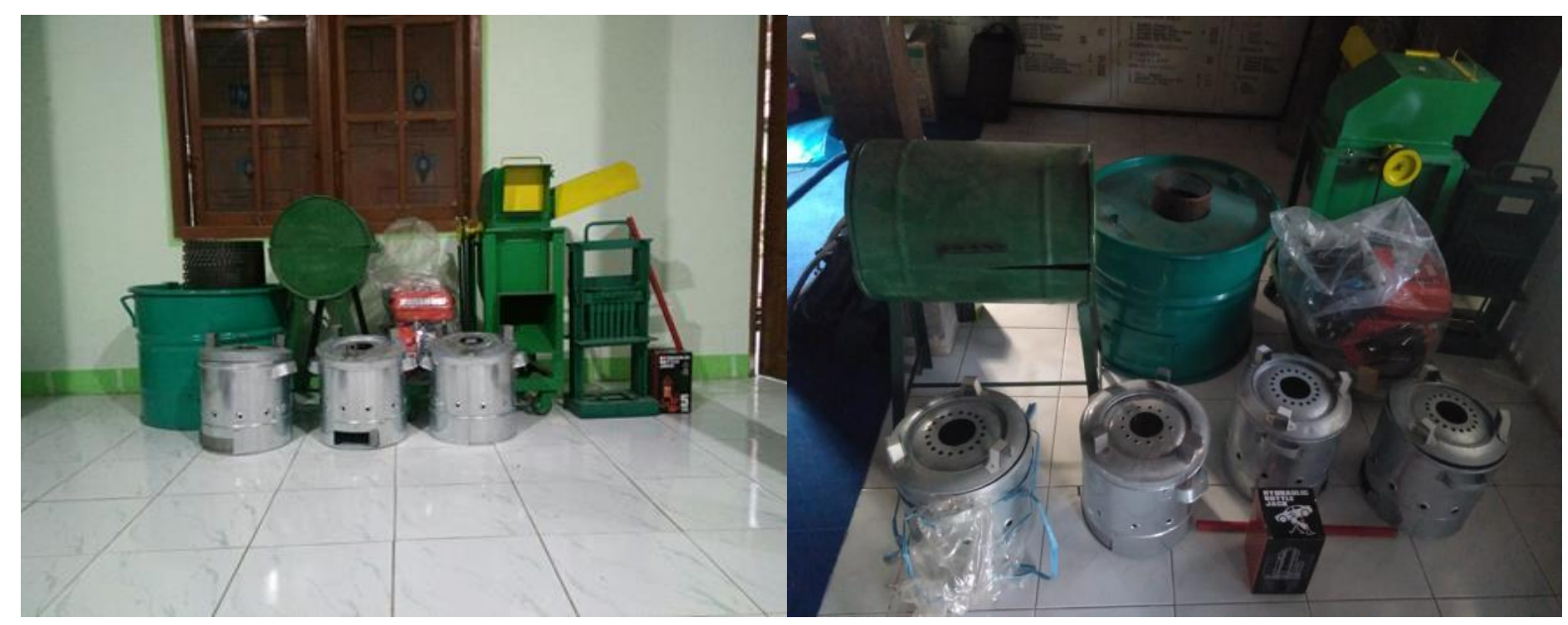

Gambar 2. Teknologi (mesin dan peralatan) untuk diterapkan 
Prosiding Seminar Nasional seri 8

"Mewujudkan Masyarakat Madani dan Lestari” Yogyakarta, 27 September 2018

Diseminasi Hasil-Hasil Pengabdian

\section{HASIL DAN PEMBAHASAN}

\begin{tabular}{|c|c|c|}
\hline NO & NAMA KEGIATAN & HASIL \\
\hline 1 & 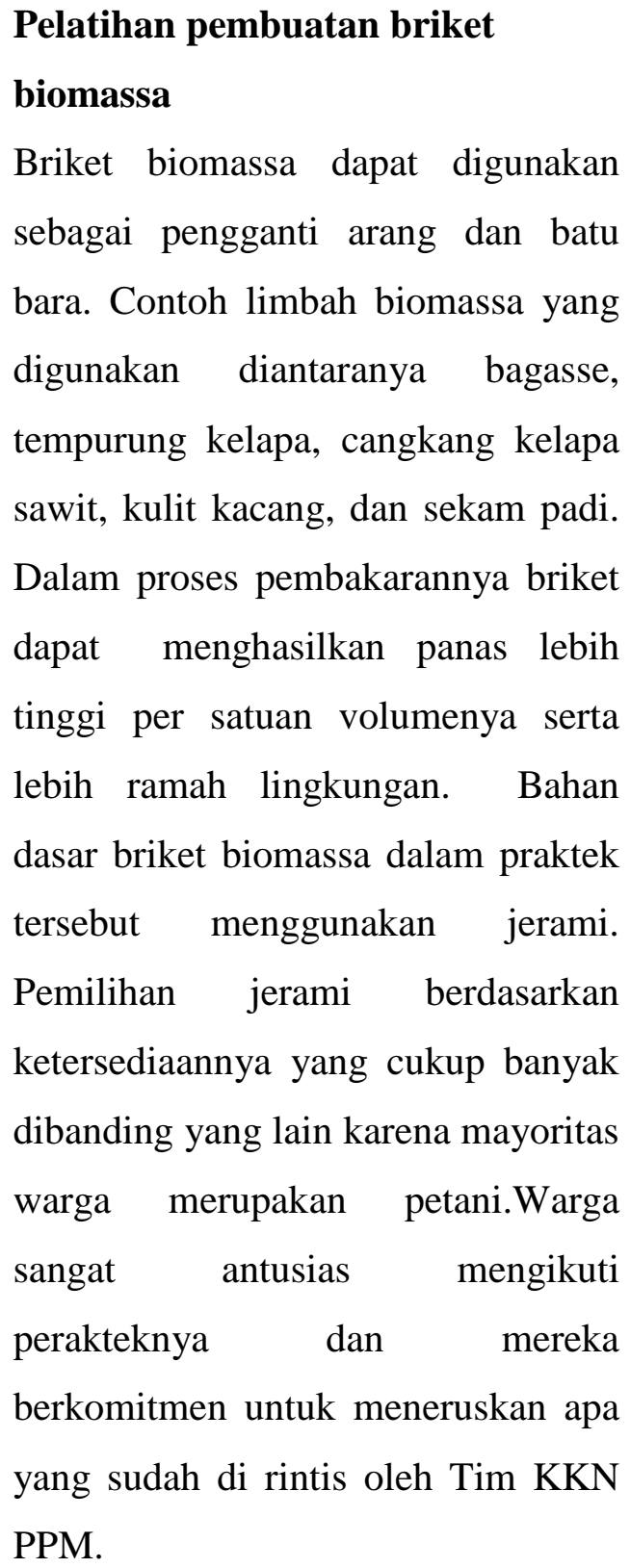 & \\
\hline 2 & $\begin{array}{l}\text { Pelatihan pembuatan bokashi } \\
\text { Bokashi dipopulerkan pertama kali di } \\
\text { Jepang sebagai pupuk organik yang } \\
\text { bisa dibuat dengan cepat dan } \\
\text { efektif.Terminologi bokashi diambil } \\
\text { dari istilah bahasa Jepang yang } \\
\text { artinya perubahan secara bertahap. } \\
\text { Bokashi merupakan cara pembuatan }\end{array}$ & \\
\hline
\end{tabular}




\begin{tabular}{|c|c|}
\hline & $\begin{array}{l}\text { pupuk kompos dengan } \\
\text { menggunakan starter aerobik maupun } \\
\text { anaerobik untuk mengkomposkan } \\
\text { bahan organik. Starter yang } \\
\text { digunakan berupa Inokulen yang } \\
\text { merupakan campuran dari larutan } \\
\text { gula dengan bahan-bahan organik } \\
\text { seperti nenas, bawang, tempe dan } \\
\text { pisang. EM4 juga bisa dijadikan } \\
\text { sebagai pengganti inokulen, bisa } \\
\text { dibeli di toko - toko bahan pertanian. } \\
\text { Bahan utama pembuatan bokhasi } \\
\text { berasal dari kotoran ternak sapi. } \\
\text { Jumlah kotoran ternak sapi di daerah } \\
\text { pengabdian cukup banyak, akan } \\
\text { tetapi belum terkelola dengan baik. } \\
\text { Beberapa manfaat pupuk Bokashi } \\
\text { antara lain: } \\
\text { 1. Memperbaiki sifat fisik, kimia } \\
\text { dan biologi tanah } \\
\text { 2. Meningkatkan kuantitas dan } \\
\text { kualitas hasil pertanian } \\
\text { 3. Meningkatkan kandungan } \\
\text { material organik tanah sehingga } \\
\text { mengurangi kepadatan tanah } \\
\text { dan dapat mempermudah } \\
\text { mengurangi kelengketan tanah } \\
\text { meningkatkan } \\
\text { malat dan mesin bajak }\end{array}$ \\
\hline 3 & $\begin{array}{l}\text { Pelatihan pembuatan silase } \\
\text { Silase diberikan kepada hewan } \\
\text { ternak ruminansia atau dijadikan } \\
\text { biofuel melalui digesti anaerobik. }\end{array}$ \\
\hline
\end{tabular}


Prosiding Seminar Nasional seri 8

"Mewujudkan Masyarakat Madani dan Lestari” Yogyakarta, 27 September 2018

Diseminasi Hasil-Hasil Pengabdian

$\begin{aligned} & \text { Silase biasanya dapat menggunakan } \\ & \text { bahan rerumputan termasuk juga } \\ & \text { daun - daunan jagung, kelapa sawit, } \\ & \text { nangka, dan lain - lain. Proses silase } \\ & \text { ini melibatkan bakteri-bakteri atau } \\ & \text { mikroba yang membentuk asam } \\ & \text { susu, yaitu Lactis Acidi dan } \\ & \text { streptococcus yang hidup secara } \\ & \text { anerob dengan derajat keasaman } \\ & 4 \text { pH } \quad 4 \text { ). Rerumputan harus } \\ & \text { dihaluskan terlebih dahulu. Bahan - } \\ & \text { bahan silase dimasukkan dalam } \\ & \text { plastik dan di tutup rapat sehingga } \\ & \text { prosesnya bisa berjalan dengan baik. } \\ & \text { Prosesnya bisa berlangsung } 6 \text { sampai } \\ & 8 \text { minggu. Silase yang baik bahkan } \\ & \text { bisa bertahan sampai } 2 \text { tahun. Wadah } \\ & \text { silase harus dalam keadaan tertutup } \\ & \text { agar tidak cepat rusak. Ciri - ciri } \\ & \text { silase yang sudah jadi rasa dan } \\ & \text { wanginya asam, warna pakan ternak } \\ & \text { masih hijau, teskstur rumput masih } \\ & \text { jelas, tidak berjamur, tidak berlendir, } \\ & \text { dan mengumpal. }\end{aligned} \mid$




\begin{tabular}{|c|c|}
\hline 4 & $\begin{array}{l}\text { Pelatihan pembuatan pupuk } \\
\text { cascing } \\
\text { Kascing merupakan singkatan dari } \\
\text { "Bekas Cacing", yaitu merupakan } \\
\text { salah satu jenis pupuk organik. } \\
\text { Kascing adalah pupuk organik yang } \\
\text { berupa kotoran cacing yang telah } \\
\text { dikeringkan. Lahan pertanian yang } \\
\text { banyak mengandung cacing } \\
\text { menandakan daerah tersebut banyak } \\
\text { mengandung unsur hara yang } \\
\text { bermanfaat untuk pertumbuhan } \\
\text { tanaman. Selain itu cacing dalam } \\
\text { tanah berfungsi untuk menurunkan } \\
\text { pH tanah agar kembali normal. } \\
\text { Kascing belum terlalu dikenal luas } \\
\text { oleh masyarakat di daerah KKN. } \\
\text { Oleh karena itu saat pelatihan ini } \\
\text { dilaksanakan mereka sangat antusias } \\
\text { mengikuti kegiatannya. Praktek } \\
\text { Kascing ini sendiri merupakan salah } \\
\text { satu program unggulan tim KKN } \\
\text { PPM. Tidak hanya berhenti pada saat } \\
\text { KKN, kegiatan diharapakan dapat } \\
\text { dilanjutkan oleh masyarakat stempat } \\
\text { untuk meningkatkan kesuburan tanah } \\
\text { di daerahnya. }\end{array}$ \\
\hline
\end{tabular}


Prosiding Seminar Nasional seri 8

"Mewujudkan Masyarakat Madani dan Lestari” Yogyakarta, 27 September 2018

Diseminasi Hasil-Hasil Pengabdian

5
Pelatihan pembuatan biogas
Saat di lapangan tim memberikan
edukasi dan praktek terkait
pemanfaatan limbah kotoran ternak
karena hal ini masih sangat
dibutuhkan oleh warga dalam
mewujudkan lingkungan yang sehat.
Praktek yang dilakukan berkaitan
dengan pembuatan biogas. Biogas
merupakan hasil fermentasi
anaerobik yang termasuk dari bahan-
bahan organik diantaranya; kotoran
hewan, sampah biodegradable,
limbah domestik (rumah tangga)
bahkan kotoran manusia yang
mengalami kondisi anaerobik. Biogas
yang dihasilkan dapat dimanfaatkan
untuk kebutuhan rumah tangga
misalnya masak. Akan tetapi bisa
juga dikembangkan untuk
pemanfaatan skala besar tergantung
jumlah dan ketersedian limbah
ternaknya.




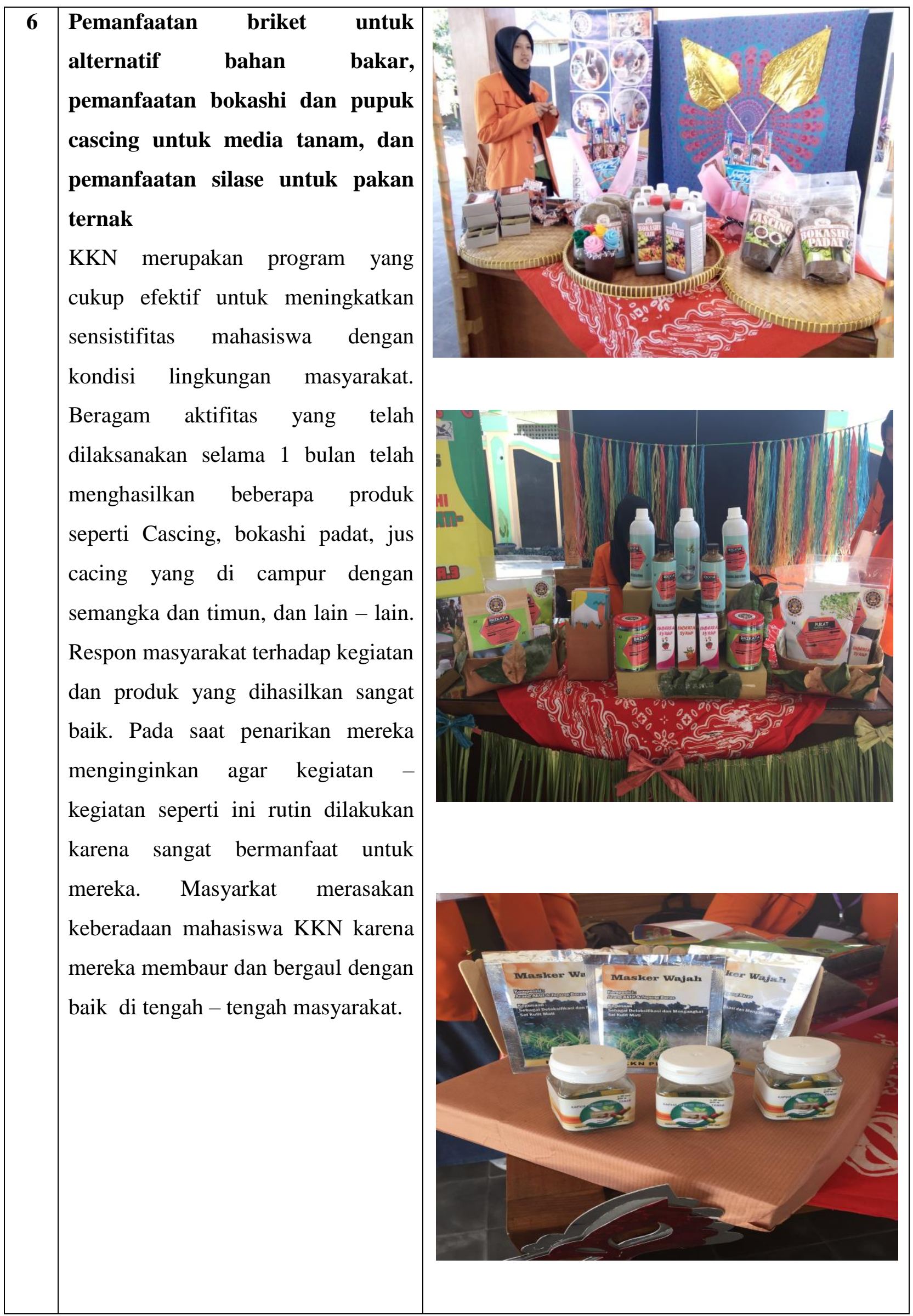


Prosiding Seminar Nasional seri 8

"Mewujudkan Masyarakat Madani dan Lestari” Yogyakarta, 27 September 2018

Diseminasi Hasil-Hasil Pengabdian

\section{KESIMPULAN}

1. Masyarakat sangat membutuhkan program pelatihan untuk meningkatkan pengetahuan mereka dalam hal pengelolaan sampah

2. Pengetahuan yang baik akan mendorong mereka untuk melakukan pengelolaan limbah dengan baik

3. Perilaku yang tidak baik dalam pengelolaan limbah akan semakin berkurang sejalan dengan komitmen masyarakat stelah mengikuti pelatihan tentang Kascing, Bokhasi, Silase, Biogas, dan juga briket bioarang.

\section{UCAPAN TERIMAKASIH}

1. Kementrian Ristek Dikti, Direktorat Jenderal Perguruan Tinggi untuk dana pelaksanaan Program KKN PPM.

2. LPPM Universitas Ahmad Dahlan Yogyakarta untuk dukungan dan pendampingannya sehingga Program Program KKN PPM berjalan lancar.

\section{DAFTAR PUSTAKA}

Brady, N dan Buckman H. 1982. Ilmu Tanah. Bhratara Karya Aksara. Jakarta.

Dinas Pertanian Kab.Sleman, 2015, http://pertanian.slemankab.go.id/core/wpcontent/uploads/2015/04/Kabupaten-Sleman-Dalam-Angka-2016.pdf. Diakses tanggal 1 Juni 2017.

Isnaini, M., 2006. Pertanian Organik Untuk Keuntungan Ekonomi dan Kelestarian Bumi. Kreasi Wacana. Jakarta.

Kurupan. P et al.2005. "Vermicomposting as Eco tool In sustainable Solid Wate Management", Anna Uneversity

Mashur. 2001. Vermicompos Pupuk Organik Berkualitas dan Ramah Lingkunga. Intaalasi Penelitian dan Pengkajian Teknologi Pertanian Badan Penelitian dan Pengembangan Pertanian.

Profil Desa Sinduharjo, 2014, https://sinduharjo.wordpress.com/category/profil-sinduharjo/. Diakses 1 Juni 2017

Sudirja, R, 1999, Budidaya cacing tanah, Assosiasi kultur vermi Indonesia, Jatinangor. 